Natural Hazards and Earth System Sciences (2003) 3: 153-158

(C) European Geosciences Union 2003

Natural Hazards and Earth System Sciences

\title{
Search for earthquake precursors in multidisciplinary data monitoring of geophysical and biological parameters
}

\author{
A. Ya. Sidorin \\ O. Yu. Schmidt United Institute of Physics of the Earth, Russian Academy of Sciences, ul. Bolshaya Gruzinskaya 10, D-242, \\ GSP-5, Moscow, 123995 Russia
}

Received: 15 May 2002 - Revised: 22 October 2002 - Accepted: 4 November 2002

\begin{abstract}
Abstract. Short-term variations in sets of geophysical and biological parameters that were monitored at the Garm research site for a long time are considered in relation to an earthquake of magnitude $M=5.3$. Daily average data of electrical resistivity, electrototelluric field, electrochemical potential, water conductivity and hourly average data of electrical activity of weakly electric fishes were used. All the data, including bioindicators activity, were obtained by high precision instrumental methods. Contemporary disturbances of all the geoelectrical parameters were discovered when observations were carried out directly in the epicentral zone of the impending earthquake. At the distance of about 20-30 km from the epicenter short-term precursors were not found.
\end{abstract}

\section{Introduction}

Anomalous changes in various geoelectrical parameters were observed before many earthquakes in different regions of the world (Corwin and Morrison, 1977; Noritomi, 1978; Varotsos and Alexopoulos, 1988; Sidorin, 1992; Hayakawa and Fujinawa, 1994). Many reports on abnormal animal behaviour that are correlated with earthquakes are also known (Evernden, 1976, 1980; Rikitake, 1978; Wallace and Teng, 1980; Tributsch, 1982). Studies of Hatai et al. (1932), Tributsch $(1978,1982)$, Nersesov et al. (1988), Ikea et al. (1996a, 1996b, 1997, 1998) and Huang et al. (1997) showed that animals are very sensitive to electric field and could respond to disturbances of geoeletric fields before earthquakes. In other words, unusual animal behaviour before earthquakes might have some relation to geoeletrical precursors of them.

According to Buskirk et al. (1981) and Ikea et al. (1997), aquatic animals are more sensitive to electric signals than other animals. Some of them have special electro-sensory systems which are used to acquire information for orientation

Correspondence to: A. Ya. Sidorin

(sidorin@uipe-ras.scgis.ru) and communication with each other (Lissman, 1958; Knudsen, 1975; Buskirk et al., 1981). These systems may be perturbed by electric field before earthquakes. Fish is frequent among other animals in the reports related to earthquakes (Hatai and Abe, 1932; Terada, 1932; Suehiro, 1934; Sparks, and Cairns, 1972; Frohlich, and Buskirk, 1980; Mulilis and White, 1986; Nersesov et al., 1988; Sablin-Yavorskii and Sidorin, 1995).That is why an analysis of instrumental data on variations in geoelectrical fields and fish activity observed before the same earthquake is of a great interest.

From 1979 and up to the very moment of liquidation of the Garm test site in 1992 a monitoring of a set of geoelectrical parameters had been realized at a territory of the KhazorChashma observatory located in a central part of the Garm test-site (Sidorin, 1990). Apparent electrical resistivity of rocks $\rho_{k}$, electrotelluric field (ETF), electrochemical potential (ECP), water electrical conductivity in a spring source (WEC) were measured daily.

On 26 February 1983 at 20:07 GMT according to the Greenwich mean time, (at 02:07 LT on 27 February by local time) at a distance of a few kilometers from the observatory an earthquake occurred of magnitude $M=5.3$. This seismic event was one of the largest ones for almost the whole 40year period of instrumental seismic monitoring at the Garm test site. In the village of Khazor-Chashma, the observatory bearing the same name was located close by, 6 out of 25 houses were heavily damaged and appeared to be not suitable for reconstruction.

Availability of the data of multidisciplinary monitoring directly in the epicentral zone of a devastating earthquake is a rather rare phenomenon. Therefore, a revelation of shortterm precursors of the earthquake by data of electrical monitoring in the area of the Khazor-Chashma observatory is a challenging task. The obtained time series data had been analyzed earlier using formalized methods: apparent resistivity variations and ETF were considered in (Descherevsky and Sidorin, 1996), and ECP and WEC in (Descherevsky and Sidorin, 2000). The results by various time series were presented in different papers and had not been compared to each 


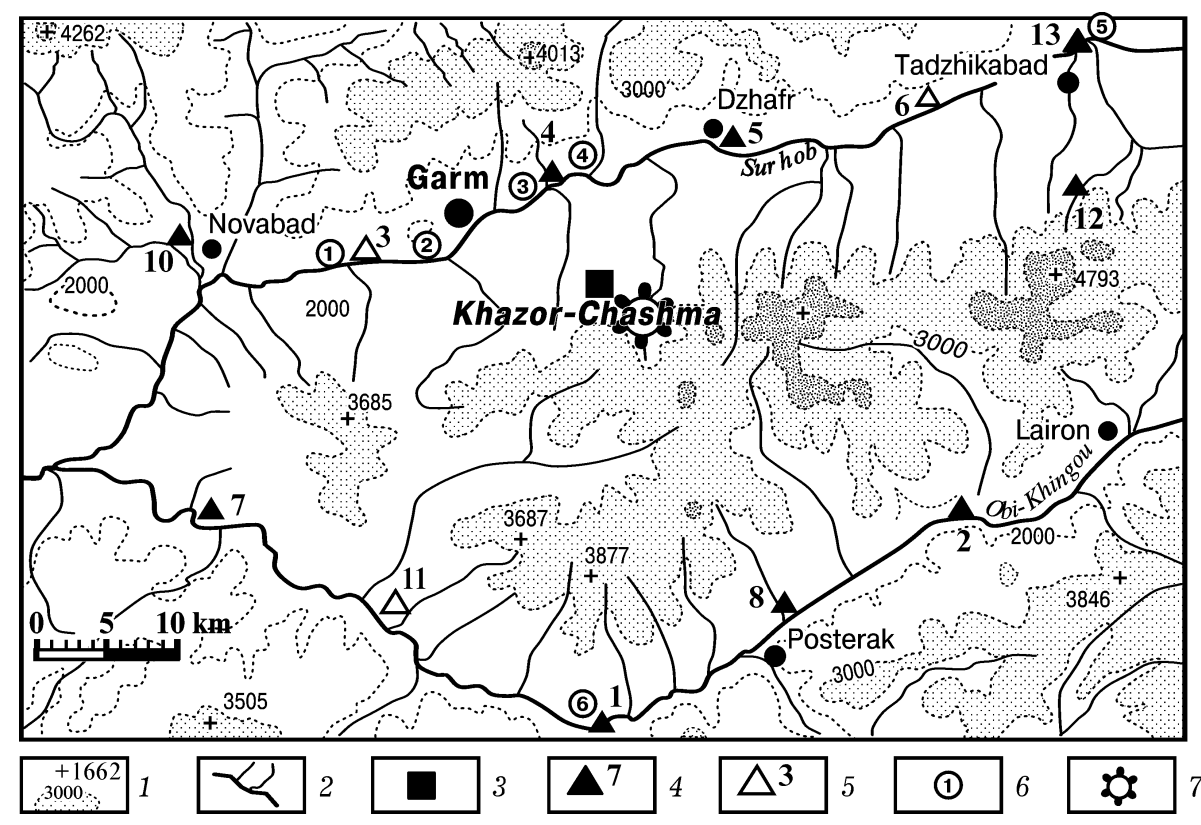

Fig. 1. A sketch of the central part of the Garm test site: 1-horizontals and marks of the heights (the relief section 1000 m); 2-rivers and inflows; 3-Khazor-Chashma observatory; 4-seismic stations of the test-site and their numbers; 5-the stations at which monitoring of the parameters considered in the paper was realized; 6-bore-holes for monitoring of underground water level; 7-epicenter of the earthquake of 26 February 1983.

other. Besides, in the stated papers time series were subjected to preliminary processing, in particular, the trends and seasonal variations were filtered.

In present paper, with particular reference to the earthquake of 26 February 1983, time series of geolectrical parameters recorded at the Khazor-Chashma observatory are being compared. Besides the geoelectrical monitoring data in the area of Khazor-Chashma, the ECP time series and the data of instrumental biological monitoring system observed at the Garm station (seismic station 3) located at a distance of $16 \mathrm{~km}$ west of the Khazor-Chashma observatory are being considered.

\section{The observation system and used data}

The Garm research site is situated within the junction zone of the Pamirs and Tien Shan, two of the major Cenozoic mountain belts of Central Asia. The region is dominated by horizontal compression. This area is one of the most seismically active intraplate regions and has been intensively studied geophysically and geologically since the devastating Khait earthquake of 1949. Detailed summaries of structure of the Garm region and description of the research site observation system can be found in (Gubin, 1960; Guseva et al., 1983; Sidorin, 1990; Lukk and Schevchenko, 1986; Lukk et al., 1995; Zhuravlev et al., 1998). The observation system used in present work is shown in Fig. 1.

Earthquake parameters are given in Table 1. For both observation points the values of the ratio of the source size $L$, which being evaluated by the formula $L=10^{(0.44 M-1.29)}$, to the hypocentral distance $R$ are given in the table.

Only in Khazor-Chashma obtained data may be related to the epicentral zone, because the distance to the observation point is less than the source's size.

Time series obtained as a result of geoelectrical monitoring in the area of Khazor-Chashma observatory have been utilized. The apparent resistivity was measured by a digital equipment. The spacings of the current electrodes of a fourpoint array $\mathrm{AMNB}$ made $\mathrm{AB}=3000 \mathrm{~m}$ and the receiving ones $\mathrm{MN}=500 \mathrm{~m}$. The ETF monitoring was set up also exploiting a measuring line of sublatitudinal orientation $500 \mathrm{~m}$ long. Two pairs of electrodes made of copper and lead were used to measure ECP. All the observations were conducted during a period of about 12 years, from 1979 till 1992.

In 1983 weakly electric fish (Gnathonemus leopoldianus) were used as bioindicators. The monitoring of their electrical activity was carried out with the help of a measuring equipment described by Borovikov and Sidorin (1987). These observations were conducted during a period of about 4 years, from 1983 till 1986.

ETF monitoring data recorded at Chil-Dora (11) and Chusal (6) stations (Ponomarev, 1987) and underground water level monitoring data (Nersesov et al., 1991) were also utilized. More detailed information on the system of observations is reported by Sidorin (1990). 
Table 1. The earthquake parameters. Note: D-epicentral distance; $H$-depth; $L$-source's size; $L / R$-ratio of the source size to hypocentral distance. Time is shown in hours (the first two digits) and minutes. The epicenter coordinates are given in degrees (the first two digits) and minutes

\begin{tabular}{|c|c|c|c|c|c|c|c|c|c|c|}
\hline \multirow[t]{2}{*}{ Date } & \multirow[t]{2}{*}{ Time } & \multirow[t]{2}{*}{$\begin{array}{l}\text { Latitude, } \\
\text { N }\end{array}$} & \multirow[t]{2}{*}{$\begin{array}{c}\text { Longitude, } \\
\text { E }\end{array}$} & \multirow[t]{2}{*}{$M$} & \multirow[t]{2}{*}{$\begin{array}{l}H, \\
\mathrm{~km}\end{array}$} & \multirow[t]{2}{*}{$\begin{array}{c}L, \\
\mathrm{~km}\end{array}$} & \multicolumn{2}{|c|}{$\begin{array}{c}\text { Observatory } \\
\text { Khazor-Chashma }\end{array}$} & \multicolumn{2}{|c|}{$\begin{array}{c}\text { Seismic Station } \\
3 \text { (Garm) }\end{array}$} \\
\hline & & & & & & & $\Delta, \mathrm{km}$ & $L / R$ & $\Delta, \mathrm{km}$ & $L / R$ \\
\hline 26 Feb. 1983 & 2007 & 3856 & 7030 & 13.3 & 5.9 & 9.8 & 7.6 & 1.28 & 22.8 & 0.43 \\
\hline
\end{tabular}

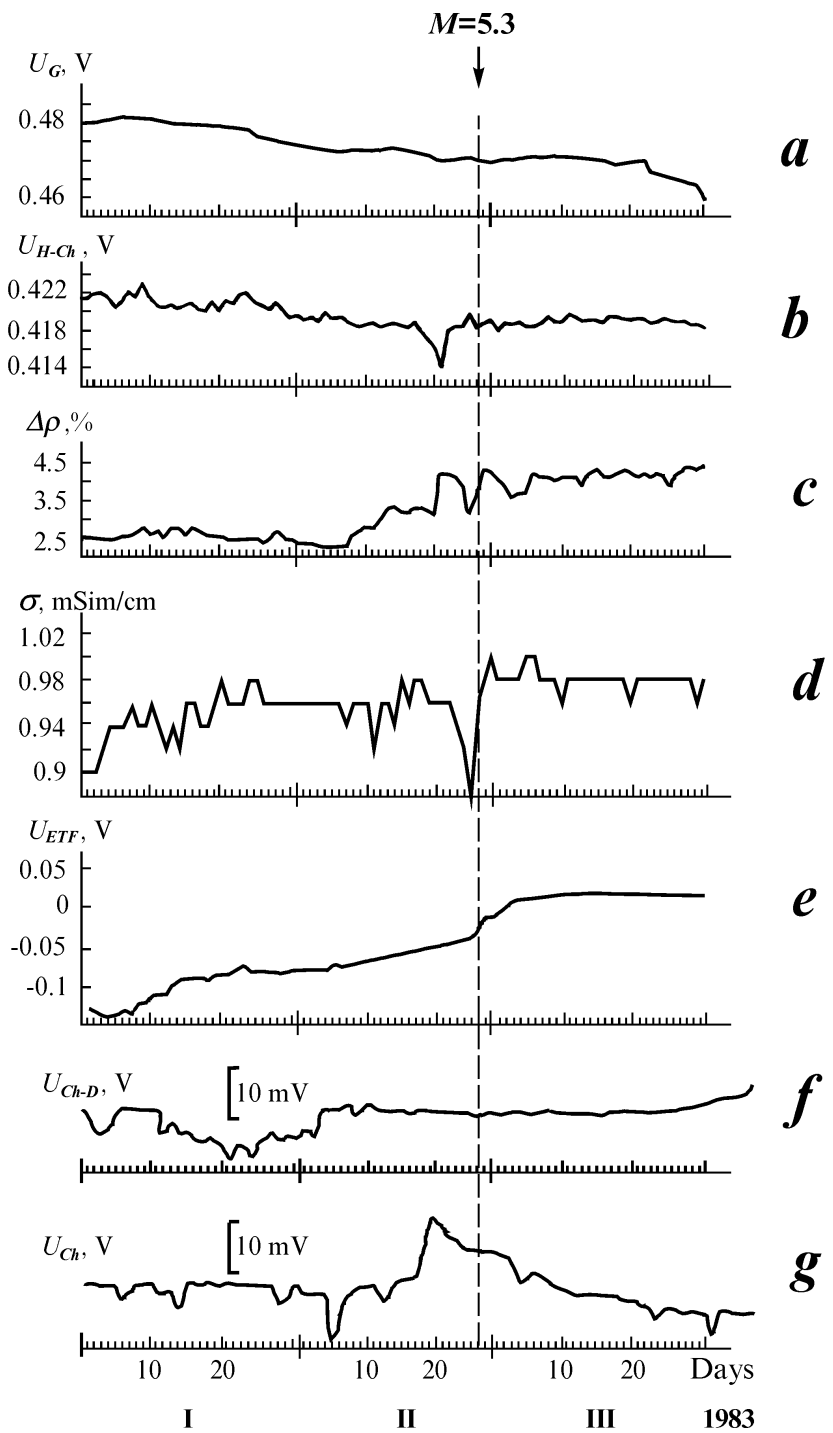

Fig. 2. The fragments of the time series of the geoelecrical monitoring data at the Garm test site in the time vicinity of the earthquake of 26 February 1983. (a) ECP at Garm station; (b) ECP at KhazorChashma observatory; (c) the electrical resistivity variations; (d) WEC; (e) ETF at Khazor-Chashma observatory; (f) ETF at ChilDora station; (g) ETF at Chusal station. All the lines are oriented in the direction $\mathrm{E}-\mathrm{W}$.

\section{Results}

In Fig. 2 fragments of time series of average daily values of geoelectrical parameters, which had been observed at the stations of Garm (3), Chil-Dora (11), Chusal (6), and KhazorChashma observatory are presented.

No marked variations prior to the earthquake were observed at the Garm station located approximately $23 \mathrm{~km}$ from the epicenter. Different kinds of anomalies were recorded before and after the earthquake at Khazor-Chashma observatory. In particular, on 27 February i.e. immediately after the earthquake, electrotelluric field varied rather sharply. Other time series evidence anomalies observed before the earthquake. From 18 to 21 February significant variations were noted by the electrochemical equipments. On 25 February a very low water electrical conductivity was observed.

The anomaly is evidenced by sharp variations in the time series of the electrical sounding data. On 8 February intensive growth of resistivity began. From 21 February to 6 March, some resistivity variations of oscillating character were observed in particular in the period when the earthquake with magnitude $M=5.3$ occurred at an epicentral distance of about $7 \mathrm{~km}$. In the monitoring period 1979-1992 no similar anomaly was observed. Reliability of the anomaly is rather high since the result reliability of measurements was confirmed by test measurements.

The other time series' disturbances did not show unusual behaviour. However, a rather contemporary appearance of disturbances of all the considered time series observed in Khazor-Chashma attracted our attention. It is very important, that all the discussed disturbances occurred during a very quiet background winter period.

ETF monitoring at stations of Chusal and Chil-Dora revealed anomalies with an amplitude of $5-10 \mathrm{mV}$ before the earthquake. Anomaly time duration was about 20 days. The anomaly at the Chil-Dora station began approximately a month earlier than at the Chusal station. It is probably related to different spatial location of the stations, in particular to a smaller distance of the Chil-Dora station from the earthquake's epicenter.

The simultaneous appearance (on 19-21 February) of anomalies of geoelectrical parameters at the stations KhazorChashma and Chusal is particularly interesting. The possibility of ionospheric disturbances can be excluded since the ETF series at the Khazor-Chashma observatory was characterized by undisturbed backgrounds at that time. 
Table 2. Anomalous underground water level changes before the earthquake (Nersesov et al., 1991). Note: signs “+” and “-” denote increasing and decreasing of the level, respectively

\begin{tabular}{ccccccc}
\hline Parameter & \multicolumn{7}{c}{ Borehole } \\
& 3 & 4 & 2 & 1 & 6 & 5 \\
\hline Epicentral distance, $\mathrm{km}$ & 10 & 13 & 18 & 20 & 28 & 40 \\
Amplitude, $\mathrm{cm}$ & 0.0 & +2.5 & -0.5 & 0.0 & +1.8 & +7.0 \\
Time before the earthquake, days & - & 3 & 2 & - & 4 & 2.5 \\
Coseismic step, cm & -0.2 & -32 & +1.2 & 0.0 & +0.7 & 0.0 \\
\hline
\end{tabular}

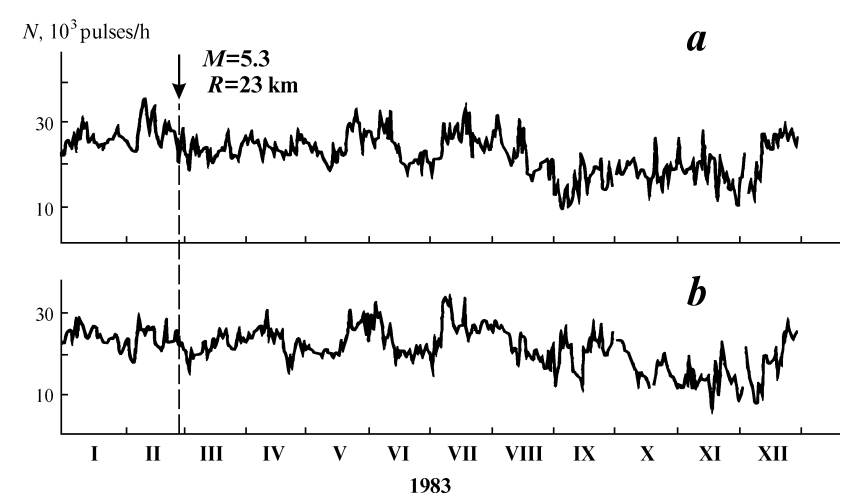

Fig. 3. Variations in average daily data by the hour on electrical activity of two samples of Gnathonemus leopoldianus in 1983 (a) the sample No. 1; (b) the sample No. 2.

From 1 January 1983 continuous instrumental observations of electrical activity variations of two samples of weakly electrical fish - Gnathonemus leopoldianus had started at the Garm station. Variations in average daily quantity of impulses being generated by the two samples of the fish during one hour are given in Fig. 3. No peculiarities confined to the earthquake are seen.

In Fig. 4 variations in every hour data on electrical activity of Gnathonemus leopoldianus in February 1983 are shown. During the last hours prior to the earthquake there were no unusual variations in electrical activity of the fishes. It should be noted that Garm station was located approximately $23 \mathrm{~km}$ far from the epicenter and there were no precursors registered by the ECP monitoring equipments (Fig. 1). Residents in villages located near the epicenter did not observe abnormal animal behaviour in the same period.

\section{Discussion}

Before the earthquake in February 1983, which occurred in a central part of the Garm test site, short-term disturbances in time series obtained as a result of geoelectrical monitoring in the area of Khazor-Chashma observatory were registered. At the same time, at the Garm station no anomalies before the earthquake were found using electrical or biological methods. The epicentral distance in this case was approximately

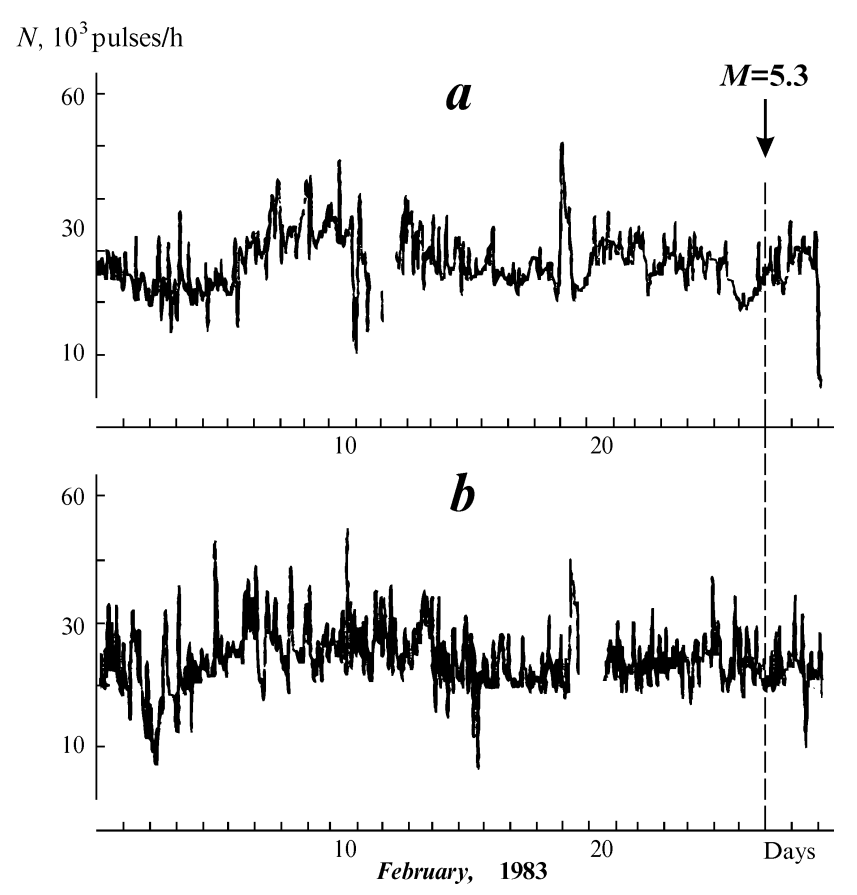

Fig. 4. Variations in the data by the hour on electrical activity of Gnathonemus leopoldianus in February, 1983. (a) the sample No. 1; (b) the sample No. 2.

$23 \mathrm{~km}$, while Khazor-Chashma observatory was located directly in the epicentral zone of the earthquake.

Results are in agreement with data described by Nersesov et al. (1991), who noted the absence of anomalous changes in strain and tilt of the Earth's surface at the stations of the Garm test site prior to the earthquake. According to the same paper, at some points of the Garm test-site significant changes in underground water level several days prior the earthquake were registered. Their distribution in the area and some other factors provide solid grounds for interpreting these anomalies as precursors of the earthquake occurred on 26 February 1983 (Table 2). But no changes in the underground water level were observed at the Garm station (borehole 1) prior to the earthquake. At the same time the largest amplitude of a hydrogeological precursor was noted in borehole 5 located not very far from the Chusal station. It is possible that this circumstance and the occurrence of a clear ETF anomaly at the Chusal station is the result of a single process in the Earth's crust. 


\section{Conclusions}

Thus, the results of the analysis of short-term variations in different parameters prior to the considered earthquake confirm the existing ideas on inhomogeneity of spatial manifestation of earthquakes' precursors. Probability to detect shortterm precursors increases in the epicentral area of impending earthquakes.

Acknowledgements. This work was supported by the Russian Foundation of Basic Research, grant No. 01-05-65503.

\section{References}

Borovikov, A. G. and Sidorin, A. Ya.: Apparatus for observing weak-electric fishes in the search for biological earthquake precursors, Seismic Instruments, NY: Allerton Press, Inc., 18, 3033, 1987.

Buskirk, R. E., Frohlich, K., and Litham G. V.: Unusual animal behavior before earthquakes: A review of possible sensory mechanisms, Rev. Geophys. Space Phys., 19, 247-270, 1981.

Corwin, R. F. and Morrison, H. F.: Self-potential variations preceding earthquakes in Central California, Geophys. Res. Lett., 4, 171-174, 1977.

Descherevsky, A. V. and Sidorin, A. Ya.: Algorithms and results of formalized search for earthquakes precursors in the time series data of geoelectrical monitoring. Federal System of Seismological Networks and Earthquake Predictions, (in Russian), 3, 3, 11-27, 1996.

Descherevsky, A. V. and Sidorin, A. Ya.: Search for electrochemical earthquake precursors at the Garm test area, Seismicheskie Pribory, (in Russian), 33, 96-114, 2000.

Evernden, J. F. (Ed): Abnormal animal behavior prior to earthquakes, Proc. of Conference, Menlo Park, Calif.: USGS, 2, 237 p., 1980.

Evernden, J. F. (Ed): Abnormal animal behavior prior to earthquakes, 1. Proc. of Conf., Menlo Park, Calif.: USGS, 1, 429 p., 1976.

Frohlich, C. and Buskirk, R. E.: Can fish detect seismic waves?, Geophys. Res. Lett., 7, 569-572, 1980.

Gubin, I. Ye.: Patterns of seismic activity in the territory of Tajikistan, Moscow, Acad. Nauk SSSR, (in Russian), 464 p., 1960.

Guseva, T. V., Lukk, A. A., Pevnev, A. K., Skovorodkin, Yu. P., and Shevchenko, V. I.: Geodynamics of the Garm polygon region in Tadzikistan, Izvestiya, Phys. Solid Earth, 19, 506-518, 1983.

Hatai, S. and Abe, N.: The responses of the catfish, Parasilurus Asotus, to earthquakes, Proc. Imper. Acad. Japan, 8, 375-378, 1932.

Hatai, S., Kokubo, S., and Abe, N.: The earth currents in relation to the responses of the catfish, Proc. Imper. Acad. Japan, 8, 478481, 1932.

Hayakawa, M. and Fujinawa, Y.(Eds): Electromagnetic phenomena to earthquake prediction, Tokyo, Terra Scientific, 677 p., 1994.

Huang, Q., Ikea, M., and Huang, P.: Electric field effects on animals: mechanism of seismic anomalous animal behaviors (SAABs), Earthquake Research in China, 11, 111-118, 1997.

Ikea, M., Komatsu, T., Kinoshita, Y., Teramoto, K., Inoue, K., Gondou, M., and Yamamoto, T.: Pulsed electric field before Kobe and Izu earthquakes from Seismically-induced Anomalous Animal Behavior (SAAB), Episodes, 20, 252-260, 1997.
Ikea, M., Takaki, S., and Takashimizu, D.: Electric shocks resulting in seismic anomalous animal, behaviors (SAABs), J. Phys. Soc. Japan, 65, 710-712, 1996a.

Ikeya, M., Furuta, H., Kajiwara, N., and Anzai, H.: Ground electric field effects on rats and sparrows: Seismic anomalous animal behaviors (SAABs), Japan Journal of Applied Physics, 35, 45874594, 1996 b.

Ikeya, M., Matsuda, T., and Yamanaka, C.: Reproduction of mimosa and clock anomalies before earthquakes. Are they "Alice in the Wonderland Syndrome"?, Proc. Japan Acad., Ser. B., 60 64, 1998.

Knudsen, E. L.: Spatial aspects of electric fields generated by weakly electric fish, J. Comp. Physiol., 99, 103-118, 1975.

Lissman, H. W.: On the function and evolution of electric organs in fish, J. Exp. Biol., 35, 456-486, 1958.

Lukk, A. A. and Shevchenko, V. I.: Character of the deformation of the Earth's crust in the Garm region (Tajikistan) from geological and seismic data, Izvestiya, Phys. Solid Earth, 22, 527-539, 1986.

Lukk, A. A., Yunga, S. L., Shevchenko, V. I., and Hamburger, M. W.: Earthquake focal mechanisms, deformation state, and seismotectonics of the Pamir-Tien Shan region, Central Asia, J. Geophys. Res., 100, B10, 20321-20343, 1995.

Mulilis, J.-P. and White, M. H.: Behaviors of the catfish Corydoras Aeneus for use in earthquake prediction, Earthquake Prediction Research, 4, 47-67, 1986.

Nersesov, I. L., Protasov, V. R., and Sidorin, A. Ya.: Experience in using slightly electrical fish in search for earthquake precursors, Izvestiya, Earth Physics, 24, 9, 750-755, 1988.

Nersesov, I. L., Perederin, V. P., Bokanenko, L. I., and Galaganov, O. N.: Local strain and tilts of the Earth's surface and underground water level variation at the Garm polygon in 1981-1987, Earthquakes and their preparation processes, Moscow, Nauka, (in Russian), 164-181, 1991.

Noritomi, K.: Application of precursory geoelectric and geomagnetic phenomena to earthquake prediction in China, Chinese Geophysics, Washington, AGU, 1, 2, 377-391, 1978.

Ponomarev, A. V.: A study on rock electric state variations in relation to searches for eartthquake precursors, Ph.D. Thesis, Moscow, IFZ AN SSSR, (in Russian), 1987.

Rikitake, T.: Biosystem behavior as an earthquake precursor, Tectonophysics, 51, 1-7, 1978.

Sablin-Yavorskii, A. D. and Sidorin, A. Ya.: Correlation between the motor activity of fish and geophysical processes, Biophysics, 40, 1117-1122, 1995.

Sidorin, A. Ya. (Ed): The Garm geophysical polygon, Moscow, IFZ AN SSSR, (in Russian), 240 p., 1990.

Sidorin, A. Ya.: Earthquake precursors, Moscow, Nauka, (in Russian), 192 p., 1992.

Sparks, R. E. and Cairns, J.: The responses of bluegill sunfish (Lepkmis macrochirus Rafinesque) to seismic shock, Hydrobiologia, 39, 273-276, 1972.

Suehiro, Y.: Some observations on the unusual behavior of fishes prior to an earthquake, Bull. Earthq. Res. Inst. Tokyo Univ., Suppl., 1, 228-231, 1934.

Terada, T.: On some probable influence of earthquakes upon fishes, Bull. Earthq. Res. Inst. Tokyo Univ., 10, 390-401, 1932.

Tributsch, H.: When snakes awake: animals and earthquake prediction, MIT Press, Cambridge, MA (USA), 248 p., 1982.

Tributsch, H.: Do aerosol anomalies precede earthquake?, Nature, 276, 606-608, 1978.

Varotsos, P. and Alexopoulos, K.: Physical properties of the varia- 
tions of the electric field of the earth preceding earhquakes, Part I., Tectonophysics, 110, 73-98, 1988.

Wallace, R. E. and Teng, T. L.: Prediction of the Sungpan-Pingwu earthquakes, August 1976, Bull. Seismol. Soc. Amer., 70, 1199_ 1223, 1980.
Zhuravlev, V. I., Konovalov, Yu. F., Lukk, A. A., and Sidorin, A. Ya.: Geoelectrical model of the crust in the Garm region compared with geological and seismological data, Izvestiya, Phys. Solid Earth, 34, 647-655, 1998. 